\title{
Learning and Teaching College Algebra at University level: Challenges and Opportunities: A Case Study of USIU
}

\section{Mrs. Nadezhda Pavlovna Okello}

\begin{abstract}
This study sets out to establish the reasons why many students had difficulty in solving mathematical problems. Questionnaires distributed to six hundred and fifty students undertaking College Algebra over a period of three semesters of my teaching College Algebra at USIU in 2007 yielded responses which confirmed that indeed most of the students had difficulty in mathematics and gave varied reasons why this was the case. Lack of persistence, determination and confidence in oneself were some of the reasons established as the main obstacles that hinder most students from enjoying an otherwise exciting and interesting course. Further analysis of the performance of every student right from his/her final mathematics results at school upto his/her final mathematics examination results at the Fall 2007 in College Algebra gave additional reasons, stated else where in this study, for their poor performance in College Algebra.
\end{abstract}

Key words: Mathematics, college algebra, confidence, persistence, determination, performance.

\section{Introduction}

The importance of mathematics is recognized worldwide. It is an essential discipline that needs to be augmented in education to equip students with skills necessary for achieving in higher education, career aspiration, and personal fulfillment. The following are some of its significance to education:

\section{Mathematics enhances problem solving skills and analysis skills of students.}

It enhances their logical function and aesthetic skills. It enables students to apply their skills to both familiar and unfamiliar situations. Mathematics prepares students for jobs 
on statistics. People who compute insurance rates are statisticians called actuaries. These specialists are able to predict events.

\section{Mathematics is applied in our daily life.}

Mathematical applications are necessary in facing challenges of our daily life. Mathematics is applied in cryptography, that is, the art of making codes and decoding them. TV companies make people pay for their programs by installing "dishes" on roof tops to encode TV signals which must be decoded by a rented decoding device (decoder) for a customer to view the programs.

\section{Mathematics is a base for all technologies.}

All innovations are a byproduct of science and mathematics. It is applied in medicine, engineering, natural science, social science, physical science, technology, business and commerce.

\section{Mathematics is applied in different types of careers.}

It is encountered in all aspects of human life. Therefore, it is important in education to help students and people perform their tasks efficiently and be productive. Mathematics is necessary in learning computer science. Importance of computer application in our lives cannot be over emphasized. Computers are to be found in banks, in hospitals, in universities e.t.c. they are used by accountants, doctors, research scientists, economists, students and many others.

Since College Algebra is a branch of mathematics it therefore follows that it is necessary for students to understand it and pass it. And it is this demand that has motivated me to establish the challenges and opportunities in learning and teaching College Algebra at USIU.

From the questionnaires we gave to my students and analysis of their performance in College Algebra both at Placement examination and final examinations at USIU it was evident that students performed poorly at both these examinations (tables 4.1, 4.2, 4.3). 
This preliminary evidence that many students are unsuccessful in learning College Algebra formed the basis for the need to research on the causes for the failure.

\section{Importance of the research}

Poor performance in College Algebra at USIU is not peculiar as it has also been noted elsewhere. Acelajado M.A. notes in her experimental study at De La Salle University, Phillipines that there is a generally low achievement in mathematics and relatively low self-efficacy among studens, an observation that I also established at USIU (1). Don Small at the U.S. Military Academy, West Point, New York in his paper also states that about $40-60 \%$ range is the general failure rate percentage of students in College Algebra in USA (6).

\section{Position of College Algebra at USIU}

At USIU, College Algebra is a compulsory subject in the general education program. General Education contributes 33\% marks for any degree course at this university.

USIU has two schools namely: the School of Arts and Sciences and the School of Business Administration. At the School of Arts and Sciences degree courses such as International Relations, Journalism, Psychology and Languages are studied while Accounting, Business Administration, International Business Adminstration, Information Systems and Technology e.t.c degree courses are taken at the School of Business Administration. College Algebra at USIU is studied at both these schools and a student must pass in it to proceed with his/her chosen specialized degree course.

\section{Conceptual Framework}

Previous research and studies about the challenges and opportunities of teaching College Algebra at the university worldwide by my peers in this field have come up with interesting observations that need to be considered at the USIU. Below is my review of some of these research works, studies and articles in this field:

Acelajado M.J. (2005); experimental study inferred that performance in higher mathematics largely depends on the learner's mathematical ability and understanding of 
basic mathematical concepts which calls for an improvement in the student's persistence and confidence in solving mathematical problems that can be achieved by use of modular teaching approach (1).

Ames, C. (1992); concluded that solving mathematical problems is attributed to putting more effort, time and patience in the learning and applying of mathematical concepts. It calls for practicing in solving both familiar and unfamiliar problems (2).

Boyles, N. \& Contadino, D. (1997); concluded that confidence (self efficacy) which is self assurance in one's capabilities affects a person's success in mathematics (3).

Dale Alspach (2008); stated that College Algebra is a stumbling block to many students. Many students do not pass their course. He proposes to redesign the delivery of College Algebra to students by introducing the use of computer software to teach them through short video presentations and online testing. This makes learning student- oriented and the lecturer only participates in giving individualized assistance only when the student is in difficulty of solving a specific problem. He also notes in his research that such a method has been applied in other universities with increased success rate (4).

Davis, P \& R.Hersh (1990); identified impatience in solving mathematical problems by a student as one of the reasons for resistance, resentment and rejection hence wrong attitude towards mathematics. The attendant result is poor performance (5).

Don Small (2002); identified high school preparation, placement, syllabus content, attitude, pace, pedagogy e.t.c. as the main factors that contribute to poor performance in College Algebra. He calls for the creation of programs that empower students to become confident problem solvers. These problems should be motivated by real-world problems. He calls for all people to improve the role of College Algebra in our educational system (6). 
Parker, R. \& M. Hetherington (1999); identified personality factors such as persistence, self -concept and attitudes towards mathematics play a major influence on mathematical ability of a student (7).

Shepherd M.D. (2005); and his subsequent research observes that most students do not read their mathematics textbooks for the purpose of learning anything but to find their homework problems or to find similar examples as their assignment to mimic. And very few students read mathematical materials before it is covered in class lessons unless requested to do so by the lecturer. He concludes that fluency in reading mathematics correctly seemed to help a student in understanding mathematics (8).

From these studies and others it is true to conclude that success in mathematics is partly as the result of confidence and hard work by the student.

However these studies and observations do not address the concerns of students as they never incorporated the student's point of view and no feedback from students was sort by these authors.

\section{Mathematical disability in people.}

There are five main deficits which cause mathematical disabilities in many people. These deficits arise during the child's educational history although neurological or environmental causes are not entirely ruled out. The FIVE main deficits are as follows:

\section{Computational Weakness.}

Many students while they understand mathematical concepts are inconsistent at computing mainly because they misread signs or carry numbers incorrectly or may not write numerals in the correct column. Such students have deficiency as far back as from the primary school.

\section{Difficulty in transferring knowledge.}


Many students experience difficulty in mathematics because of their inability to connect abstract or conceptual aspects of mathematics with reality.

Understanding what mathematical symbols represent in the physical world proves to be difficult to most students and this makes it not uncommon to find that some students cannot visualize an equilateral triangle.

\section{Making Connections.}

Some students cannot comprehend the relationship between numbers and the quantities they represent and this makes mathematical skills not to be anchored in any meaningful manner, making it harder for them to recall and apply mathematical knowledge in new situations.

\section{Incomplete understanding of the language of mathematics.}

For some students mathematical disabilities is as a result of problems with the language of mathematics. Such students have difficulty with reading, writing and speaking mathematical terminologies which normally are not used outside the mathematics lesson. They are unable to understand written or verbal mathematical explanations or questions and therefore cannot relate mathematical knowledge to physical world.

\section{Difficulty in comprehending the visual and spatial aspects and perceptual difficulties.}

Many students have the inability to visualize the mathematical concepts, for example, they are unable to judge the relative size among three dissimilar objects. It is difficult for them, for example, to visualize the difference in relative size between a cylinder, cube and a sphere of the same volume. This makes students to memorize mathematical formulae and facts hence the difficulty in applying such knowledge in solving unfamiliar mathematical problem.

\section{Objectives of the research}

It has been observed over time that mathematics, under which College Algebra falls, has been very challenging to many students in many countries $(\mathbf{1} ; \mathbf{6})$. 
At USIU Fall 2007 College Algebra Examination results showed that only $23 \%$ of the students performed well (Table 9.3). And such results have been noted over years at the university. This poor performance calls for an establishment of the reason why College Algebra is challenging to many students. Even at Placement Examination level the same trend of low performance is noted (Table 9.2). And all the way back to high school grades the story is still the same (Table 9.1). This study therefore seeks to investigate the causes of poor performance in College Algebra at USIU by interrogating the students through questionnaires, interviews, monitoring their performance all through the course over a period of time and analyzing their results at three stages: their final high school mathematics grades, their Placement Examination results in mathematics and finally their final College Algebra Examination results. A theoretical overview of how to improve the performance of students in College Algebra shall be proposed at the end of this study and the way forward proposed.

\section{Research questions}

The following are research questions:

- Why do the students find learning College Algebra challenging?

- Why do lecturers find teaching College Algebra challenging?

\section{Methodology}

We gave out questionnaires to six hundred and fifty students undertaking College Algebra over a period of three semesters at USIU to interrogate them over what they considered to be their main challenges in learning College Algebra.

I also identified a sample of these students numbering five hundred and twenty and noted their high school final mathematics grades and results of their Placement Examination. I further took a sample of fifty six students out of these students and noted their final examination results in College Algebra. Analysis of these results was done and has led us to the findings that follow below.

\section{Findings}


Analysis of the mathematics' entry grades of students after high school (Table 9.1) shows that most of the students do not pass well in mathematics at school prior to being admitted into USIU where they must undertake College Algebra irrespective of whatever specialized courses they intend to study. Only thirty three percent (33\%) of the students who were admitted at the beginning of fall 2007 to undertake USIU Mathematics Placement Examination passed well at school (Table9.1).At USIU Mathematics Placement Examination only forty nine percent (49\%) passed well to undertake College Algebra with relative ease (Table 9.2).A follow up of the sample of these students showed that only twenty three percent (23\%) passed well College Algebra at the end of Fall 2007 (Table 9.3). This shows that there is a correlation between the performance in mathematics at high school and at the final examination of College Algebra at the university. A more conclusive observation is recommended for further research. Such a research should include an inquiry into the ways of improving the performance of students in College Algebra immediately they are admitted into the university.

Table No. 1: USIU Mathematics Entry Grades (Results after high school) - 2007

\begin{tabular}{|l|l|l|l|}
\hline No. of students & $\begin{array}{l}\text { Percentage of students } \\
\text { who passed well }\end{array}$ & $\begin{array}{l}\text { Percentage of students } \\
\text { on borderline to failure }\end{array}$ & $\begin{array}{l}\text { Percentage of } \\
\text { students who } \\
\text { failed }\end{array}$ \\
\hline 520 & 33 & 53 & 14 \\
\hline
\end{tabular}

Table No. 2: USIU Mathematics Placement Examination Results - 2007

\begin{tabular}{|l|l|l|}
\hline No. of students & Percentage of students who passed & $\begin{array}{l}\text { Percentage of students who } \\
\text { failed }\end{array}$ \\
\hline 520 & 49 & 51 \\
\hline
\end{tabular}

Table No.3: USIU College Algebra Examination Results - Fall 2007 


\begin{tabular}{|l|l|l|l|}
\hline No. of students & $\begin{array}{l}\text { Percentage of students } \\
\text { who passed }\end{array}$ & $\begin{array}{l}\text { Percentage of students on } \\
\text { the borderline to failure }\end{array}$ & $\begin{array}{l}\text { Percentage } \\
\text { of students } \\
\text { who failed }\end{array}$ \\
\hline 56 & 23 & 66 & 11 \\
\hline
\end{tabular}

\section{Challenges of learning college algebra.}

Challenges students encounter during their study of College Algebra are many and varied depending on the student's individual experience during mathematics lessons at school level. Questionnaires we gave out to the students and interviews we carried out with individual student undertaking College Algebra over a period of three semesters at USIU yielded the following responses at what they considered to be their main challenges:

\section{Lack of interest}

Some students lack interest in College Algebra for various reasons some of which include:

- Perceptions that mathematics is difficult.

- A myth that mathematics requires inborn special ability in some human brains (special genetic abilities).

\section{Difficulty in Connecting Mathematics to the Real World.}

Some students have difficulty in connecting algebraic expressions or/and formulae with the physical world and therefore they cannot correlate mathematics knowledge with real life situations. This makes them not understand the need to know College Algebra other than to satisfy the university requirement that they must pass it.

\section{Language Barrier.}

Terminology used in teaching mathematics makes it difficult for some students to understand it. In an international university such as USIU where English is the medium of teaching, some students for whom English is a second or third language find instructions in English to be difficult to understand and worsens when strange mathematics terminology is used. 


\section{Complex Formulae.}

Some students find comprehending the many mathematical formulae which they do not readily encounter in real life to be difficult and therefore generally cannot follow mathematics lessons leading to failure in examinations.

\section{Teacher / Student Relationship.}

Many students find quite a number of mathematics lecturers to be boring or the methods they use in teaching mathematics to be wanting hence dislike of mathematics. There is also a case of poor teacher/student interpersonal relationship with students complaining that some lecturers hate them. In such learning environment some of these students fail due to lack of positive encouragement.

\section{Discussion of findings: making sense of results.}

These findings show that students who do not perform well at their final secondary school examination in mathematics do not pass their Placement Examination well.

The findings also show that the poor performers at the Placement Examination in College Algebra have difficulty in learning it during the course and perform still poorly at the final examination.

Finally, it also follows that most students are challenged mathematically and therefore perform poorly in College Algebra.

\section{Challenges of teaching College Algebra}

\section{Lack of Practice}

Most of the students who find College Algebra difficult are those who rarely practice solving algebraic problems on their own and hardly do homework. Practice empowers the students to be problem solvers rather than making them try to master algebraic formulae. It enables students to be persistent at any activity as they learn how to solve a problem 
whose answer is not apparent. Making students practice solving mathematical problems is a challenge to lecturers.

\section{Lazy Students}

Most of the students who perform badly in College Algebra are lazy and often poorly attend lessons. They therefore miss the subject content taught in the teaching lessons. To motivate lazy students is a big challenge when teaching College Algebra.

\section{Questions are not asked}

Often poor performers do not ask questions during lessons or thereafter and hence pile up unknown materials and this makes them not to keep up with the subsequent lessons. Students must be taught how to critique quantitative information to reinforce their understanding of the subject matter and this is a challenge to lecturers.

\section{Poor Use of Resources}

Students who do not use readily available resources at the university such as textbooks can hardly perform well in College Algebra. Lack of interest in reading mathematics textbooks is also an area that challenges lecturers as some students do not actually know how to read and understand a mathematics textbook.

\section{Poor Foundation}

Students who do not have a strong foundation in mathematics find College Algebra difficult. There are students who enter the university with poor grades in mathematics from high school and therefore irrespective of the effort lecturers put in their lessons' content to make College Algebra easy these students still do not perform well.

\section{Methods of Teaching}

Traditional method of teaching College Algebra is mainly examination oriented. There is need to change it so that it can centre on developing critical thinking in students. But 
because of the mathematical backgrounds of the students that enter into the university, this task is a big challenge to the lecturers.

\section{Wrong Attitude}

Some students have an attitude that mathematics is not for them or they are not born to be good at mathematics. Therefore it is a challenge to lecturers to instill into them a sense that everyone can do mathematics. Instilling confidence in some students is a challenge in teaching them.

\section{Mathematical Thinking}

The challenge for teachers of mathematics from school level to those teaching College Algebra at the university, is how to develop the process of mathematical thinking alongside the mathematical knowledge.

\section{Conclusions}

This study yielded the following conclusions:

Many factors affect performance in College Algebra at USIU and any other university with the following being the main ones:

- $\quad$ The high school grade in mathematics of the students who take College Algebra.

- $\quad$ The choice of students at the Placement Examination stage.

- $\quad$ The content of the College Algebra syllabus.

- $\quad$ The attitude towards mathematics of the student who undertakes College Algebra.

- $\quad$ The pace at which College Algebra is taught.

- $\quad$ The pedagogy of delivering College Algebra. 
- $\quad$ The confidence and persistence of the student in solving mathematical problems.

- $\quad$ Practice in solving College Algebra problems.

- $\quad$ Consistency in attending College Algebra lessons.

- $\quad$ Reading textbooks in College Algebra.

- $\quad$ Performance in College Algebra depends on the student's mathematical ability and understanding of basic mathematical concepts.

\section{Recommendations}

The content of College Algebra and pedagogy focus in the teaching of College Algebra should change and ensure it incorporates the following:

Real -world problem based topics which call for mathematics to solve questions there in.

Encouragement of mathematical modeling where real world problems are transformed into mathematics and emphasis placed on creating a model and interpreting the results. Students should learn how to use deductive reasoning to verify and apply mathematical arguments involving these models. Conduct workshops for lecturers on the preparation of modules geared toward helping students gain confidence in College Algebra.

Emphasis should be laid on communication skills needed in society as well as in academia. Students should be encouraged to read, write, present and listen. Students should learn how to read, understand and critique information and use oral and written skills to individually and collaboratively communicate mathematical models.

Small groups in class should be formed and encouraged to be involved in inquiry and inference. They should be encouraged to conduct surveys, present data, compare results and interpret them. Data can be presented in the form of mathematical expressions, graphs e.t.c as pertains to the syllabus. 
Application of appropriate technology to enhance conceptual understanding, visualization, inquiry as well as for computation. Apply appropriate technology to enhance mathematical thinking and understanding.

\section{Encouragement of student-centered instead of lecturer centered pedagogy.}

Hands-on learning activities should be emphasized rather than lectures only. Teaching should focus on the following areas:

- Questioning and generating questions.

- $\quad$ Fostering inquisitiveness.

- Developing assumptions and approximations.

- $\quad$ Activities and projects that lead students into new areas.

- $\quad$ Student presentations.

- $\quad$ Making mathematical connections to and solving problems from other disciplines involving functions.

- Data interpretation, analysis and generating of discussions based on them.

- $\quad$ Use of College Algebra to quantify real-world situations, that is, to mathematically model physical phenomena. Application of modular teaching should be emphasized.

- $\quad$ Encourage creativity so that students remain interested, focused and enthusiastic during College Algebra lessons.

- $\quad$ Engage students in the teaching process. Students can be made to interact in group discussions and activities involving brainstorming and deductive reasoning. These include charting activities, illustrating activities, manipulative activities and evaluating data. Such a learning process, improves students' social skills in addition to mathematical problem solving.

- $\quad$ College Algebra syllabus should be refocused such that all students become confident problem solvers. The syllabus should be motivated by real world problems and should address the quantitative needs of the 
course that the students are going to pursue at the university as well as the needs of citizenship.

- $\quad$ Emphasis should be laid on the interpretation of data than manipulation of algebraic formulae as this can be computerized.

\section{Further research opportunities}

There is need to repeat this type of research several times, with different students taught by different lecturers, to increase the number of students involved. The research should also cover a longer period.

It is also possible to monitor the performance of students after passing College Algebra to assess the relevance of their mathematics knowledge in the courses they proceed to learn.

The research can also be extended to final year high school students to assess the relevance of their mathematics syllabus to College Algebra and also to document their performances in mathematics throughout their high school years.

The research may also cover assessment of the relevance of the school mathematics syllabi of other neighboring countries from which we receive students who undertake College Algebra at USIU.

\section{References}

1. Acelajado, M.J. (2005). "The Modular Teaching Approach in College: An Alternative to Improving the Learner's Achievement, Persistence and Confidence in Mathematics." Experimental study at De La Salle University, Manila 2004-2005

2. Ames, C. (1992). “Classroom: Goals, structure and student motivation.' Journal of Educational Psychology, 84(3), 261-271. 
3. Boyles, N. \& Contadino, D. (1997): “The learning differences sourcebook.” L.A.: RGA Publishing Group.

4. Dale, A. (2008): "College Algebra Redesign.'" Proposal to the Department of Mathematics Oklahoma State University.

5. Daris, P \& R.Hersh. (1990): "The mathematical experience." Harmondsworth: Penguin.

6. Don, S. (2002): "An Urgent Call to Improve Traditional College Algebra Programs.' Presentation at the conference to improve College Algebra held at U.S. Military Academy Feb 7-10, 2002.

7. Parker, R. and M. Hetherrington. (1999): "Child Psychology: A contemporary viewpoint.' Boston: Mc Graw Hill.

8. Shepherd, Mary D. (2005): "Encouraging Students to Read Mathematics." PRIMUS, vol.15 (2), June, 2005, pp.124-144. 